been started by Professor A. R. Ubbelohde more than twenty years ago. Although the specific energy release in the solid-solid phase transitions likely to occur in the Earth's crust is small, when cubic kilometres of material may be involved, it is clear that very large amounts of energy may be made available. Moreover, in several laboratory systems--Barton et al. give a list of some of these, the polymorphic transitions in antimony and of austenite to martensite, for example - it does seem that phase transitions can be rapid, sometimes explosively so.

Most contributors to this discussion have assumed that in the crust or mantle of the Earth, a phase transition would spread through a body of rock consisting of a metastable phase as would a shock wave. But where would the metastable phases have come from? The suggestion now is that the way in which the material of the oceanic crust is carried beneath continental margins in the process of continental drifting provides a continually replenished source of metastable rocks, the energy released from which may provide the driving force for some of the earthquakes which occur with foci at considerable depths beneath the continental margin. The explanation is ingenious and attractive. The greatest difficulty is that of reconciling the pattern of energy release recorded by seismometers, which usually implies that shearing mechanisms are responsible for the deep focus earthquakes, with the notion that energy might be released in large volumes of material by explosive phase transitions. In other words, there seems to be a source of energy in the mantle but no geophysical evidence to suggest why it should be invoked.

Is it necessary to let such an intriguing possibility go begging? For some time now, it has been clear that more needs to be done to understand the consequences of phase transition in geological processes. Earlier this year, Dr D. R. Waldbaum (Nature, 232,$545 ; 1971$ ) argued that temperature changes accompanying the phase transitions in the mantle might be of great importance. His particular point was that the Joule-Thomson coefficients for many of the materials of which the mantle is made are likely to be negative at the pressures which occur in the Earth's crust, which im- plies that adiabatic decompression would bring about an increase of temperature and the release of heat even when no phase transitions are involved.

Although there is some dispute about the precise significance of Waldbaum's argument and about the likelihood that adiabatic processes do actually occur in the mantle of the Earth, this is yet another means by which the appearance of large amounts of energy deep in the interior of the Earth may be explained. This is why it seems quite clear that there is a need for more detailed and more accurate studies of the thermodynamic properties of rocks at high pressures as well as of the kinetics of phase transition in bulk materials.

For the time being, these are the directions in which speculation about explosive phase transformations in geology might be given a firmer basis. In short, even if there is not yet a crying need for the use of these explanations, they may at least serve as stimulants of valuable research.

\title{
Tectonic Implications of Blueschists
}

A FEW years ago Blake et al. (Tectonophys., 8, 242; 1969) noted that blueschist facies rocks seem to occur in narrow tectonic belts in association with ultramafic rocks; and this fact led them to suggest that the metamorphism which produced them may have occurred during underthrusting in a zone of anomalously high water pressure. If so, such metamorphism may be expected to occur most frequently along continental margins where oceanic crust is underthrusting and being subsumed, or even where such processes once took place but have now ceased. Such an expectation is especially attractive because blueschist facies metamorphic belts are also known to be associated often with ophiolites-an association thought to be characteristic of oceanic crust. metamorphic belts current recognized, including the Alaska terranes (1-4) and those recently discovered in Canada (5-6) by Monger (Geol. Surv. Canada Paper $68-48$, p. 12 ; 1969) and Paterson (unpublished hitherto).

This is not the first time that blueschists have been discovered in Alaska ; but what Forbes and his colleagues have done is to show that the scale of the Alaskan blueschist terranes is far greater than previously suspected. In fact, there now seems to be one large belt of blueschist metamorphism stretching from the Seward Peninsula (site 2) to the Baird Mountains (site 1). The Kaiyuh Mountain site (4), on the other hand, seems to form an isolated terrane although later discovery may link it to the Seldovia terrane at site 3 .

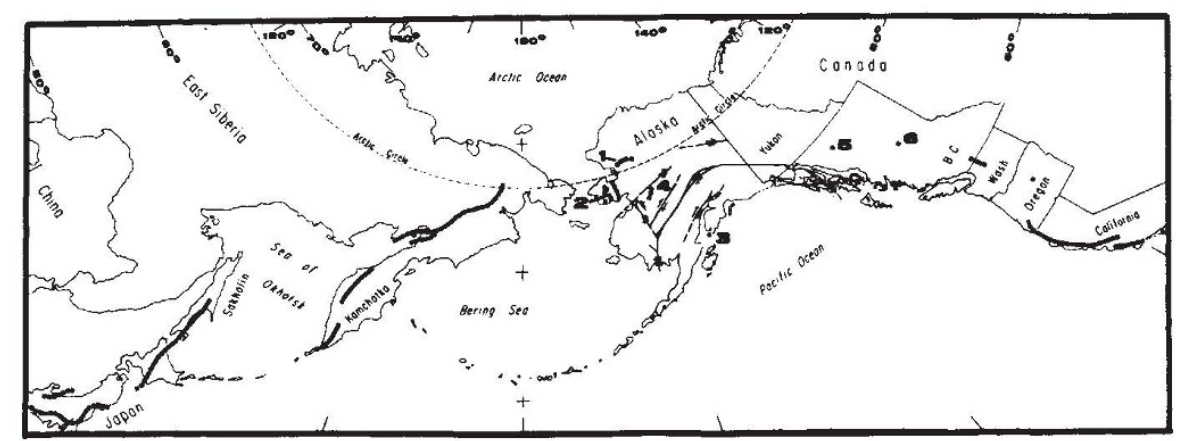

Map (polar projection) of western North America, north-east Siberia, Kamchatka and Japan (Hokkaido and Honshu), showing the regional distribution and location of blueschist facies metamorphic belts.

In next Monday's Nature Physical Science these speculations are placed into some sort of perspective by Forbes et al., who report new discoveries of blueschists in Alaska and use these discoveries to show that blueschist terranes form a well-defined belt around the northern Pacific margin. The accompanying map shows the blueschist facies
Forbes and his colleagues say that their report is a preliminary statement of the new discoveries; and thus they do not discuss tectonic implications in any detail. What does seem to be clear. however, from the distribution of blueschist metamorphism around the Pacific is that it is the result of global, rather than purely local, tectonic processes. 